\title{
The Impact of Retained Austenite on the Mechanical Properties of Bainitic and Dual Phase Steels
}

\author{
Bogusława Adamczyk-Cieślak, Milena Koralnik, Roman Kuziak, Kamil Majchrowicz, Tomasz Zygmunt, and Jarosław Mizera
}

\author{
Submitted: 7 January 2021 / Revised: 17 November 2021 / Accepted: 1 December 2021 / Published online: 4 January 2022
}

\begin{abstract}
This paper presents the microstructural changes and mechanical properties of carbide-free bainitic steel subjected to various heat treatment processes and compares these results with similarly treated ferriticpearlitic steel. A key feature of the investigated steel, which is common among others described in the literature, is that the Si content in the developed steel was $>1 \mathrm{wt} . \%$ to avoid carbide precipitation in the retained austenite during the bainitic transformation. The phase identification before and after various heat treatment conditions was carried out based on microstructural observations and x-ray diffraction. Hardness measurements and tensile tests were conducted to determine the mechanical properties of the investigated materials. In addition, following the tensile tests, the fracture surfaces of both types of steels were analyzed. Changing the bainitic transformation temperature generated distinct volume fractions of retained austenite and different values of mechanical strength properties. The mechanical properties of the examined steels were strongly influenced by the volume fractions and morphological features of the microstructural constituents. It is worth noting that the bainitic steel was characterized by a high ultimate tensile strength (1250 MPa) combined with a total elongation of $18 \%$ after austenitizing and continuous cooling. The chemical composition of the bainitic steel was designed to obtain the optimal microstructure and mechanical properties after hot deformation followed by natural cooling in still air. Extensive tests using isothermal transformation to bainite were conducted to understand the relationships between transformation temperature and the resulting microstructures, mechanical properties, and fracture characteristics. The isothermal transformation tests indicated that the optimal relationship between the sample strength and total elongation was obtained after bainitic treatment at $400{ }^{\circ} \mathrm{C}$. However, it should be noted that the mechanical properties and total elongation of the bainitic steel after continuous cooling differed little from the condition after isothermal transformation at $400{ }^{\circ} \mathrm{C}$.
\end{abstract}

Keywords bainitic steel, isothermal holding, pearlitic steel, retained austenite

\section{Introduction}

It is crucial to produce harder materials for railways to compensate for the increased wear and enable faster train speeds. When materials with lower hardness are applied, continuous and intensive abrasion of the surface layer is possible, resulting in microcrack removal. However, this phenomenon can lead to excessive and rapid tribological wear of the rails (Ref 1). The initiation of microcracks on a rail surface is inhibited in steels with high hardness, although increased propagation rates are possible because of the limited wear $(\operatorname{Ref} 2,3)$. The materials currently in use are reaching their limits, and in certain cases, they are hindering the tracks' abilities to support greater train speeds. To improve the

\footnotetext{
Bogusława Adamczyk-Cieślak, Milena Koralnik, Kamil Majchrowicz, and Jaroslaw Mizera, Faculty of Materials Science and Engineering, Warsaw University of Technology, Warsaw, Poland; Roman Kuziak, Łukasiewicz Research Network Institute for Ferrous Metallurgy, Gliwice, Poland; and Tomasz Zygmunt, ArcelorMittal Poland S.A., Dạbrowa Górnicza, Poland. Contact e-mail: milena.koralnik@pw.edu.pl.
}

mechanical properties of the rails and allow for increased train speeds, new materials and processing methods must be developed (Ref 4). Steels comprise a group of common materials among which the search for new solutions will occur, and low-carbon steels with low contents of alloying elements are particularly interesting (Ref 5-9). These materials are relatively cheap, which is an important factor for laying out a railway, where one linear meter of rail weighs over $24 \mathrm{~kg}$. Additionally, steel is well-suited for various types of thermal processing, which can drastically change its mechanical properties. One example of such a treatment is austempering, which is based on isothermal holding of the steel above the onset temperature for martensitic transformation $\left(M_{S}\right)$. This heat treatment leads to a considerable improvement in the mechanical properties of the material, without reducing its plasticity. Both of these characteristics are essential for rail steel because the increased durability increases the rail life time even under severe service conditions (Ref 10, 11). Furthermore, even a slight change in the alloying elements' content in the ironcarbon system may lead to completely different characteristics, including the capability of forming various types of microstructures in the material (Ref 12). There are numerous chemical compositions and processing methods that can be used, but choosing the proper amount and type of elements for the material is extremely challenging, especially for bainitic rails, that will be subjected to natural cooling following rolling. The same is true for thermal processing, i.e., it is possible to modify the treatment time, the austenitization and austempering 
temperatures, and the cooling time, among other parameters (Ref 13-17). Therefore, it is clear that many factors affect the selection of a material for the rails that is both suitable and enhanced relative to previous materials. Selecting a type of steel for this crucial element of the railway system requires thorough investigations regarding potential alloying additions with the widest possible range of processing methods and optimal chemical compositions.

In the present work, the chemical composition of steels was developed to obtain a desired bainitic structure after continuous natural cooling in still air immediately after the manufacturing process (without the necessity of heat treatment processes). For this reason, the analysis of the microstructure and mechanical properties of the examined steels was carried out. Numerous papers on bainitic steels deal with isothermal bainitic transformation (Ref 18-22) and the correlation between the microstructure and mechanical properties. The tests have often suggested an optimal heat treatment as a better alternative to steel obtained by continuous cooling. Also, this study was to optimize the microstructure and mechanical properties of the examined steels by simulating the thermal treatment using a Gleeble simulator. The tests clarified the correlation between the type and morphology of the austenite, as well as the cooling parameters and the temperature of the bainitic transformation of the analyzed steels.

\section{Experimental Procedures}

For the experiments, the chemical compositions of the investigated bainitic steel (BS) and ferritic-pearlitic steel (FPS) that were studied are given in Table 1. The steels were melted in the VSG 100S laboratory and cast into the crystallizer (cross section $100 \times 100 \mathrm{~mm}$ ) with water-cooled walls. The ingots of the experimental steels were each forged in the temperature range $1200-1000{ }^{\circ} \mathrm{C}$ into a bar with a cross section $70 \times 50 \mathrm{~mm}$. Following this procedure, the samples were subjected to homogenizing annealing at $1200{ }^{\circ} \mathrm{C}$.

The transformation temperatures of the BS and F-PS were calculated from the chemical composition by using commercial software (ThermoCalc and JMatPro). Next, the 60E1 rail heads were machined from each bar and welded to the base of an industrially rolled rail. Figure 1 shows an example of the "dummy" rail of BS.

The rail heads were subjected to a heat treatment under laboratory conditions that involved heating the samples to $980{ }^{\circ} \mathrm{C}$ in a resistance furnace, holding this temperature for one hour, and then naturally cooling to ambient temperature in still air. Figure 2(a-b) presents a graph of the temperature-time changes in the experiment for the BS and F-PS samples. The maximum temperature and time of holding were adjusted to obtain an austenite grain size at this stage of experiment in the range of $40-50 \mu \mathrm{m}$, as predicted during the simulation of the rail hot deformation process with a commercial Forge $\AA$ program (Ref 23). The progress of the bainitic transformation manifested in the recorded cooling curve in Figure 2(a) by the recalescence effect. The visible effect began at approximately $490{ }^{\circ} \mathrm{C}$ and ended at $320{ }^{\circ} \mathrm{C}$. The temperature was monitored with thermocouples inserted into the drilled hole located $2 \mathrm{~mm}$ below the running surface of the rail. Figure 2(c) indicates the location from which samples were taken to test their mechanical properties according to the EN 13674-1, microstructural observations and Gleeble simulations. For the second investigated steel, with a ferritic-pearlitic structure, the same locations were chosen for testing.

This treatment corresponded to the initial state of the F-PS and BS. After that, the samples were heat treated by isothermal bainitic transformation, as shown in Table 2. Thermal processing experiments were conducted with a Gleeble 3800 simulator on cylindrical samples (total length $125 \mathrm{~mm}$, diameter $10 \mathrm{~mm}$ ). During the bainitic treatment, the transformation of austenite was incomplete, and in a further step of natural cooling, the austenite may change to bainite, or to martensite below the Ms temperature. A computer system was used to design the manufacturing technology of pearlitic and bainitic steels, which consisted of the FEM (Finite Element Model) simulation module of thermo-mechanical phenomena and microstructure evolution integrated with the module of phase transformations occurring during cooling. Model parameters were identified from dilatometric tests, and physical simulations were used to validate and verify the models. Detailed information on this issue is included in (Ref 24). The chemical composition of the experimental steels was designed to obtain bainite as the main component, and the second constituent (composed of martensite and austenite) did not exceed $10 \%$.

The microstructural changes induced by the applied thermal processing were observed using light optical microscopy (LOM) and scanning electron microscopy (SEM) in the backscattered electrons (BSE) mode. For microscopy examinations, the samples were prepared by grinding with emery paper and then mechanically polishing with a monocrystalline diamond suspension. Further preparation involved etching with $0.2 \mathrm{wt} . \%$ Nital reagent. The volume fractions of bainite and martensite were determined by the AxioVision software (Carl Zeiss Microscopy GmbH, Jena, Germany) based on the morphology and grayscale of bainite and martensite.

Specimens for transmission electron microscopy (TEM) were prepared by mechanical polishing to create disks (thickness $\approx 100 \mu \mathrm{m}$ ). The disks were electrolytically thinned using a Struers electrolyte based on $\mathrm{HNO}_{3}$, and the electropolishing was performed at a voltage of $55 \mathrm{~V}$ for $15 \mathrm{~s}$. The obtained thin foils were examined in a Jeol JEM 1200 microscope operating at $120 \mathrm{kV}$. The volume fraction of the retained austenite (RA) and the content of carbon in the austenite $(C \gamma)$ were analyzed via $\mathrm{X}$-ray diffraction (XRD) at room temperature using a Bruker D8 Discover diffractometer with filtered $\operatorname{CoK} \alpha \quad(\lambda=$ $0.178897 \mathrm{~nm})$ radiation. The three reflections from austenite

Table 1. Chemical compositions of the BS-bainitic steel, and F-PS—ferritic-pearlitic steel (wt.\%)

\begin{tabular}{lcccccccrrrrr}
\hline Sample & $\mathbf{C}$ & $\mathbf{S i}$ & $\mathbf{M n}$ & $\mathbf{C r}$ & $\mathbf{N i}$ & $\mathbf{M o}$ & $\mathbf{C u}$ & $\mathbf{T i}$ & other & Fe \\
\hline BS & 0.35 & 1.04 & 1.44 & 0.83 & 0.33 & 0.15 & 0.01 & 0.001 & 0.03 & balance \\
F-PS & 0.29 & 1.01 & 1.04 & 1.27 & 0.03 & 0.02 & 0.02 & 0.024 & 0.04 & balance \\
\hline
\end{tabular}



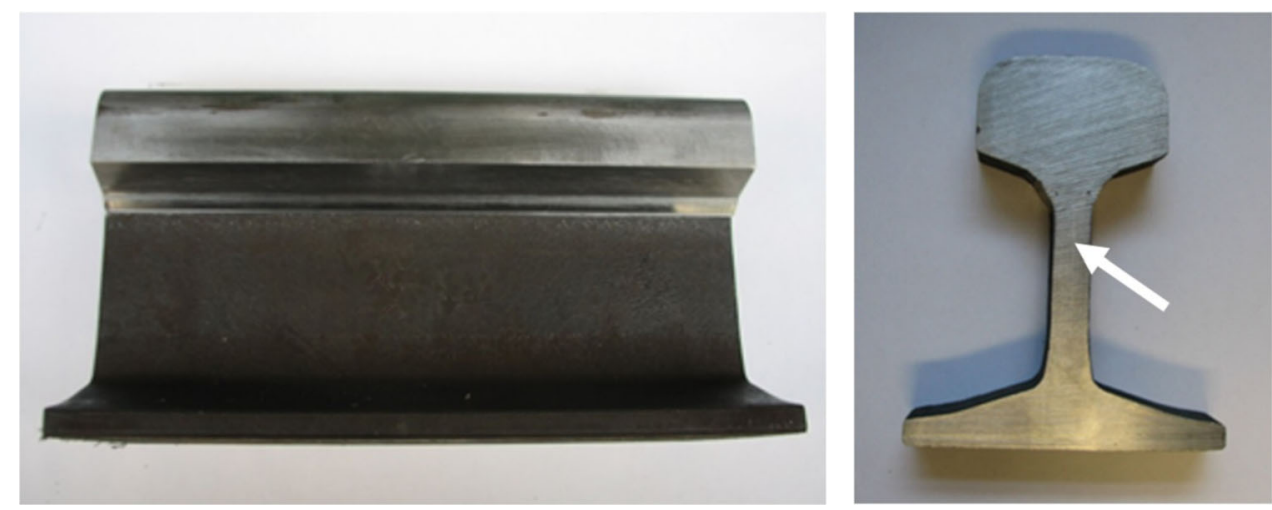

Fig. 1 The dummy 60E1 rail produced with experimental bainitic steel (arrow indicates the welded joint)
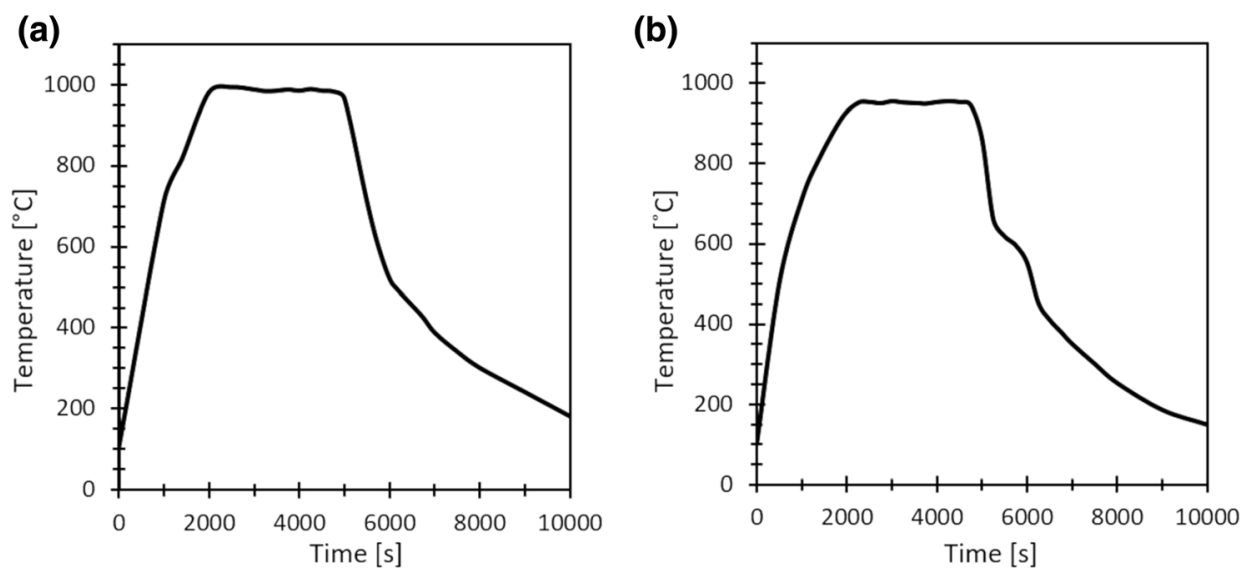

(c)

Fig. 2 Temperature-time curve for the laboratory heat treatment of the BS (a) and F-PS (b) "dummy" rail; location from which samples were taken for microstructural observations, mechanical properties tests, and Gleeble simulations (c)

Table 2. Summary of the processing schedule; $T_{A}$ austenitization temperature, $T_{1}$-bainitic treatment temperature

\begin{tabular}{|c|c|c|c|c|c|c|c|c|}
\hline \multirow[b]{3}{*}{ Bainitic Steel } & \multirow[b]{3}{*}{ Ferritic-pearlitic Steel } & \multirow[b]{3}{*}{$\boldsymbol{T}_{\boldsymbol{A}},{ }^{\circ} \mathrm{C}$} & \multirow[b]{3}{*}{ Heating rate, $\mathrm{C} / \mathrm{s}$} & \multirow[b]{3}{*}{ Time, $\mathrm{s}$} & \multicolumn{4}{|c|}{ Cooling } \\
\hline & & & & & \multicolumn{2}{|c|}{$T_{\mathrm{A}} \rightarrow T_{1}$} & \multirow[b]{2}{*}{ Holding time at $T_{1}, s$} & \multirow[b]{2}{*}{$T_{1} \rightarrow \mathrm{RT}$} \\
\hline & & & & & $T_{1},{ }^{\circ} \mathrm{C}$ & {$\left[{ }^{\circ} \mathrm{C} / \mathrm{s}\right]$} & & \\
\hline BS_A & F-PS_A & 1250 & 3 & 600 & 480 & 30 & 900 & Heating off \\
\hline BS_B & F-PS_B & & & & 450 & & 900 & \\
\hline BS_C & F-PS_C & & & & 400 & & 900 & \\
\hline
\end{tabular}

(200), (220) (311) and from bainitic ferrite (200), (211) (220) were considered to estimate the RA content by a direct comparison method (Ref 25) according to Eq 1:

$$
V_{i}=\frac{1}{1+G\left(I_{\alpha} / I_{\gamma}\right)}
$$

where $V_{i}$ is the volume fraction of austenite for each peak, $I_{\alpha}$ and $I_{\gamma}$ are the integrated intensities of bainitic ferrite and austenite peaks, and the value of $\mathrm{G}$ is selected according to the study by Wang et al. (Ref 26). Then, the separation of the bainitic ferrite and martensite diffraction peaks was measured using the MDI JADE software, and the lattice parameters were determined. The $\mathrm{C}_{\gamma}$ values were calculated from the lattice parameter $\left(a_{\gamma}\right)$ by using the relation (2) (Ref 27):

$$
C_{\gamma}=\frac{a_{\gamma}-0.3555}{0.0044}
$$

where $C_{\gamma}$ is the carbon content in retained austenite in [\%], and $a_{\gamma}$ is the lattice constant of the retained austenite $[\AA]$. The lattice parameter was estimated from an average based on the (200), (220) and (311) austenite peaks. All calculations were performed for three diffraction patterns in each state. The experimental conditions were as follows: voltage $=35 \mathrm{kV}$; current $=40 \mathrm{~mA}$; angular range of $2 \theta$ from 40 to $130^{\circ}$, measurement step $\Delta 2 \theta=0.025^{\circ}$; counting time per step $=6 \mathrm{~s}$.

The tensile tests were carried out at room temperature using a hydraulic mechanical test machine (MTS 810), equipped with a $100 \mathrm{kN}$ load cell, and samples were prepared according to the PN-EN ISO 7500-1:2018-05 guidelines. The tensile tests were 
performed at an initial strain rate of $10^{-3} \mathrm{~s}^{-1}$. From the obtained stress-strain curves, the yield strength $\left(\sigma_{0.2}\right)$, ultimate tensile strength $\left(\sigma_{m}\right)$, and total elongation (A) were determined based on the average value of three samples. Additionally, the combination of $\sigma_{m}$ and $\mathrm{A}$ was represented by the $\mathrm{R}_{\mathrm{x}}$ parameter, which is defined as $R_{x}=\left(\sigma_{\mathrm{m}} \cdot \mathrm{A}\right)$. Following the tests, the fractured samples were also analyzed using SEM. The analysis of the work hardening behavior of many metals and alloys can be described by the Hollomon (Ref 28) relation (3):

$\sigma=K \varepsilon^{n}$

The values of the strain hardening exponent $(n)$ and the strength coefficient $(K)$ were obtained from a log-log plot of the true stress $(\sigma)$ and true strain $(\varepsilon)$ up to the maximum load.

The hardness of each sample was measured using the Brinell method, using a tungsten carbide ball with a $2.5 \mathrm{~mm}$ diameter, under a load of $1.8 \mathrm{kN}$ with a dwell time of $10 \mathrm{~s}$, according to the EN ISO 6506-1:2005 guidelines. The average value of the hardness measurements was determined based on 10 indentations for each steel sample.

\section{Results and Discussion}

The calculated $\mathrm{T}_{0}$ line for the experimental BS sample and the austenite content when the carbon content reaches the $T_{0}$ line during the bainitic transformation under isothermal conditions is shown in Fig. 3. It is clear that as the transformation temperature decreased, the volume fraction of untransformed austenite also decreased; however, the carbon content increased in this phase. In general, the carbon content in austenite defines its stability during cooling to ambient temperature. It was calculated with the JMatPro program that the austenite started to be partially stable during cooling when the carbon content in this phase exceeded $0.82 \%$; however, as the carbon content in the retained austenite exceeds $1.5 \%$, this phase retains its structure almost entirely during the cooling process. According to the calculations presented in Fig. 3, the carbon content in austenite increased as the bainitic transformation progressed during cooling. This means that the martensite-austenite (MA)

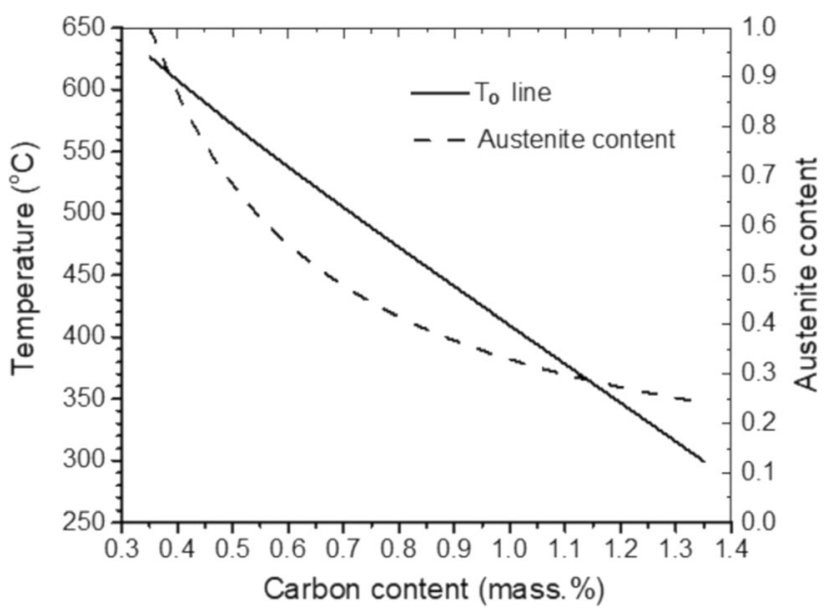

Fig. 3 The $T_{0}$ line and volume fraction of austenite as a function of temperature calculated using the ThermoCalc program for bainitic steel layers located at the bainitic lath boundaries contained more retained austenite at the end of the transformation.

The calculated TTT diagrams for the experimental bainitic steel and ferritic-pearlitic steel are shown in Fig. 4. The temperatures from which TTT diagrams were calculated were 800 and $820{ }^{\circ} \mathrm{C}$ for bainitic and pearlitic steels, respectively. According to the numerical simulations, it was expected that the austenite grain size developed in the rail during forging should be in the range of $40-45 \mu \mathrm{m}$. Upon analyzing the TTT diagrams, it was clear that the proportions among the phase transformation incubation periods in F-PS differed from those in BS. The TTT diagram in Fig. 4(a) shows that the ferritic and pearlitic transformations were substantially shifted in time with respect to the bainitic transformation. The temperature range for the latter was very wide. In the F-PS steel (Fig. 4b), the transformation curves were left-shifted to a slightly lesser extent than in BS, but the pearlite was still delayed for a long time, thus guaranteeing a bainitic microstructure during bainitic treatment. This was a result of the lower content of $\mathrm{C}, \mathrm{Mn}$ and Mo in the chemical composition of F-PS, which impacted the location of the transformation curves.

\subsection{Microstructure}

Figure 5 shows the microstructures of the investigated steel samples, and the volume fraction of different phases is presented in Table 3. The observations performed with LOM, SEM, and TEM indicated that the microstructure of the BS before isothermal annealing (Fig. 5a) was composed of bainitic laths and a second phase — retained austenite, which took the form of islands or thin layers located between the bainite laths. This type of bainite is called degenerated upper bainite (DUB), and it is formed because of an incomplete transformation of the prior austenite, combined with its stabilization due to the diffusion of carbon (Ref 29). Further SEM observations revealed the presence of small parallelly aligned laths within the austenite island. This constituent is generally known as a martensite/austenite island (M/A), which is formed from partially untransformed austenite in the final phase of cooling to room temperature ( $\operatorname{Ref} 30$ ). The average size of M/A islands is $30 \mu \mathrm{m}$. The formation of ferrite and pearlite was strongly inhibited the small carbon content in the investigated steel and the increased content of alloying elements (e.g., Mn, Mo). Carbon and manganese are austenite stabilizers, and they lower the temperature of martensite transformation; however, $\mathrm{C}$ has a stronger stabilizing effect than Mn (Ref 31, 32). Manganese also slows the transformation from austenite to bainite during processing (Ref 33). Carbon in the BS is bounded in the retained austenite and alternatively, in the martensite. In addition, an appropriate silicon content increases the carbon activity in the solid solution, which suppresses the formation of carbides (Ref 18, 34) and inhibits cementite precipitation from the austenite during bainite transformation (Ref 35). The formation of bainite is accompanied by the carbon enrichment of austenite until the displacive mechanism of growth becomes thermodynamically unfavorable (Ref 36). The main component of the F-PS microstructure (Fig. 5b) was pearlite (a lamellar structure composed of ferrite and cementite) with around $10 \%$ of the tiny ferrite grains located on the boundaries of the pearlite colonies. The pearlite colonies were randomly oriented, but the lamellas were aligned in the same orientation in each grain. High content of $\mathrm{Cr}$ and proper value of $\mathrm{Mn}$ determine the formation of fine pearlite colonies and the partition of these 


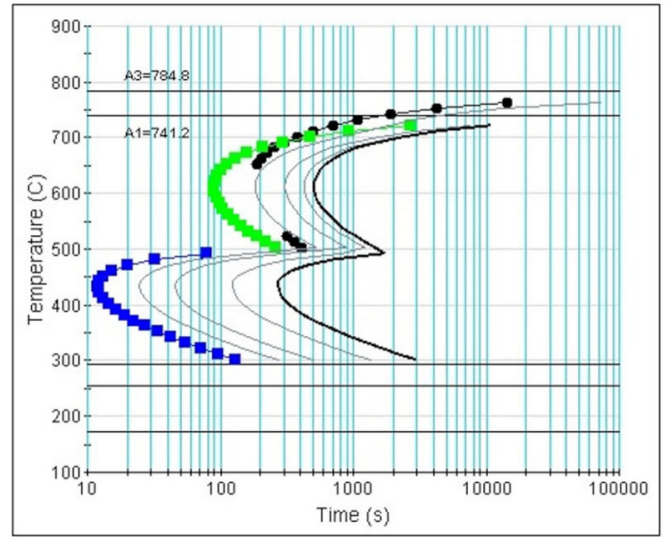

(b) TTT

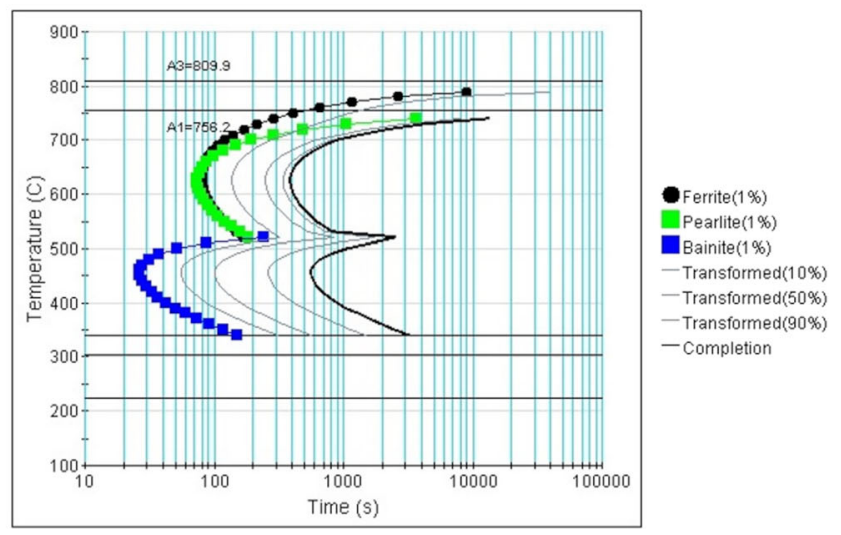

Fig. 4 The TTT diagrams for experimental BS (a) and F-PS (b) calculated with the JMatPro program

elements into cementite ( $\operatorname{Ref} 7,37-39)$. The average interlamellar spacing was approximately $0.3 \mu \mathrm{m}$, and the pearlite nodules had sizes around $40 \mu \mathrm{m}$.

The microstructures of the examined steels observed by LOM and SEM after being subjected to various bainitic treatment conditions are presented in Figure 5(c-h). The micrographs indicate that the structure of the samples depended on the chemical composition in the continuous cooled state, as well as the isothermal bainitic transformation temperature. The microstructures of the samples that were subjected to a heat treatment at $480{ }^{\circ} \mathrm{C} / 900 \mathrm{~s}$ (Fig. $5 \mathrm{c}, \mathrm{d}$ ) were mainly composed of martensite and bainite, with a small fraction of retained austenite in the form of islands. These types of microstructures were formed due to the insufficient enrichment of austenite in carbon (Ref 40). For these reasons, martensite formed during cooling to ambient temperature after the isothermal treatment at $480{ }^{\circ} \mathrm{C}$ for both steels. At the initial stage of the bainitic transformation at $480{ }^{\circ} \mathrm{C}$, only a minor increase of the carbon content in the austenite and a partial transformation to martensite occurred. The volume fraction of martensite in the investigated steels depended heavily on the $M_{s}$ and $M_{f}$ temperatures related to the carbon content in the austenite. The stability of the austenite increased as the carbon content increased, as the bainite transformation progressed (Ref 41).

Based on a comparison of the investigated ferritic-pearlitic and bainitic steels, it was determined that the microstructures of the samples differed from one another. The difference is clear from observations related to the fraction of the individual phases: The applied heat treatment led to a greater amount of martensite in the structure of the F-PS, relative to BS (Table 3). Specifically, the martensite occupied most of the analyzed microstructure in F-PS, compared with that in BS. The retained austenite is present mainly in the form of separate islands (M/A islands) with an average size of about $25 \mu \mathrm{m}$. In the BS, the bainite laths were smaller than those in the steel with the ferritic-pearlitic structure in the initial state. In addition, the volume fraction of the bainite in BS was higher, which confirmed that the bainite transformation occurred to a greater extent in BS than in F-PS. The fraction of the retained austenite was also slightly higher, and the average size of the islands did not exceed $20 \mu \mathrm{m}$. Comparing the chemical composition of both steels, it was determined that increasing the $\mathrm{Cr}$ content in the F-PS led to the development of martensite islands after isothermal transformation due to an increase in the incomplete transformation phenomenon following isothermal treatment at $480{ }^{\circ} \mathrm{C}$ (Ref 42, 43). However, the addition of chromium in both steels was sufficient to inhibit the formation of allomorphic ferrite, which is a product of high-temperature transformations (Ref 43, 44). Also, elements such as $\mathrm{Mn}$ and Mo strongly affect the stability of the phases after heat treatment. A higher proportion of Mo in BS steels causes suppress the primary ferrite and pearlite and enhances bainite formation. (Ref 45, 46). On the other hand, Mn lowers the Ms temperature and stabilizes austenite but reduces the rate of bainite transformation. Too much manganese can affect the formation of blocky retained austenite (Ref 47). For this reason, the manganese content does not exceed $1.5 \%$.

The images in Fig. 5(e,f) show the microstructures of BS and F-PS, respectively, after full austenitization followed by isothermal transformation at $450{ }^{\circ} \mathrm{C}$. Heat treatment led to the formation of bainite (degenerated upper bainite) and austenite in two forms: as thin films between the bainite laths and as coarser blocks/islands between the bainite laths. The applied heat treatment also led to the formation of heterogeneous microstructures, where bainite laths were arranged in packets that crossed the entire grains of primary austenite. Bainite has different lath widths, and in the regions where more bainite was formed, the distance between the laths did not exceed $0.4 \mu \mathrm{m}$. Austenite islands also formed in various sizes, from a few to several dozen micrometers. For the steel with an initial ferriticpearlitic structure, the average size of austenite islands was $17 \mu \mathrm{m}$, while for the BS, the average size was $12 \mu \mathrm{m}$. Inside the islands, needles of martensite were observed, and these needles were formed from a fraction of the retained austenite (containing relatively less carbon), which generated M/A constituents during subsequent cooling (Ref 48). In the F-PS, the structure was more homogeneous, and the bainite was more fragmented. The same type of microstructure was obtained for a similar heat treatment described in the literature (Ref 49), where bainite and blocks that were interpreted as retained austenite were identified.

Reducing the isothermal bainitic treatment temperature to $400{ }^{\circ} \mathrm{C}$ increased the degree of bainitic transformation and resulted in the highest fraction of retained austenite (in the form of both islands and thin films) in the investigated steels (Fig. 5 g,h). In some areas, the bainite laths were highly refined, and the thickness of both the bainite and the austenite films was small varying between 0.3 and $0.4 \mu \mathrm{m}$ ). The average size of the 
(a)

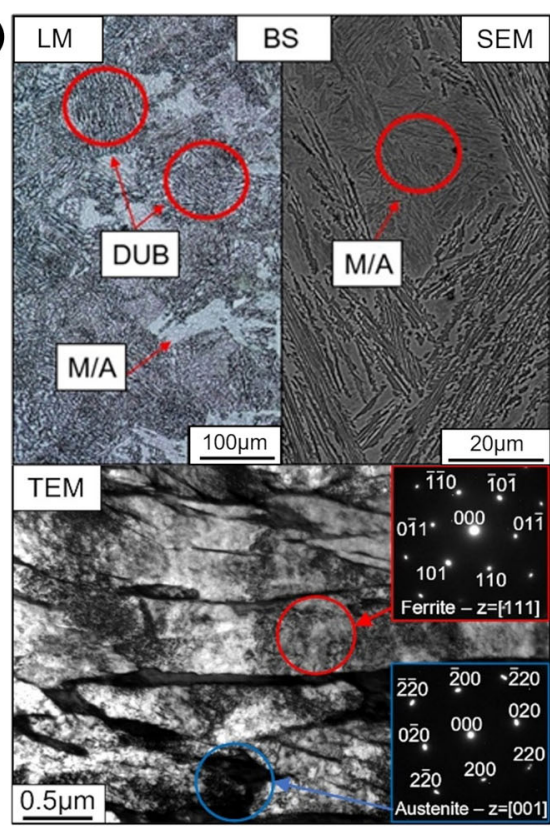

(c)

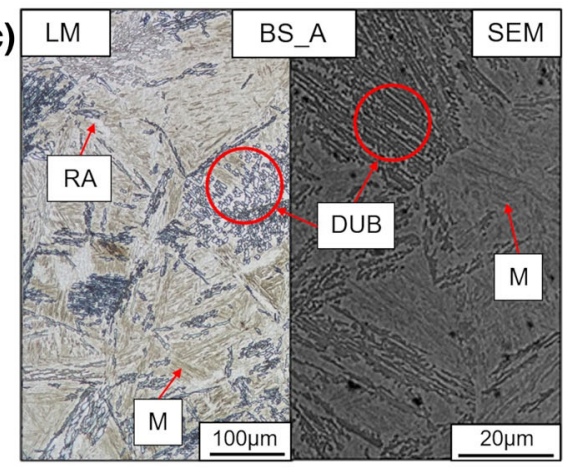

(e)

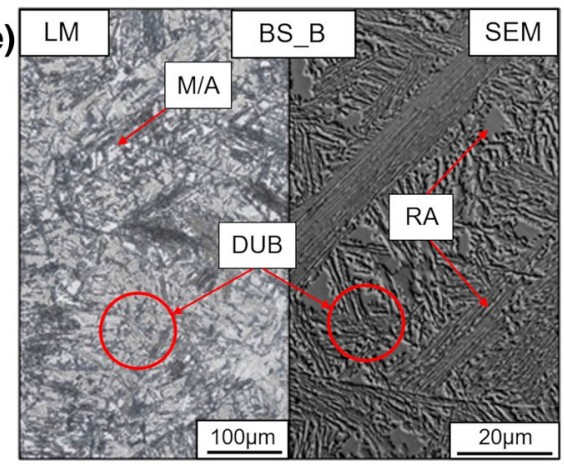

(g)

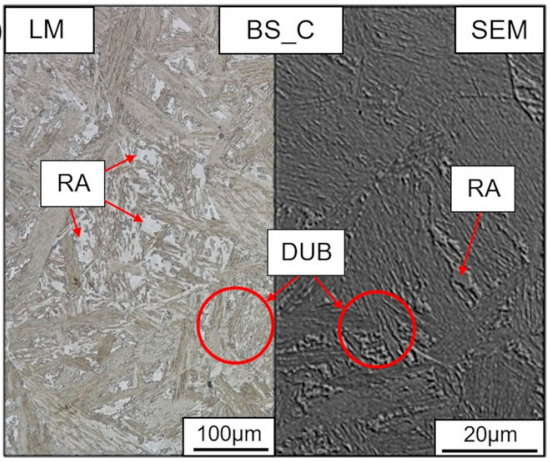

(b)

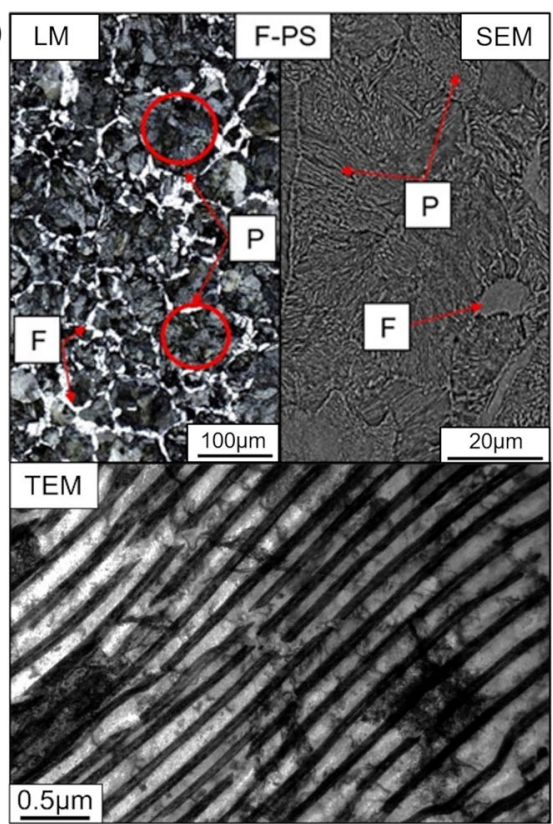

(d)

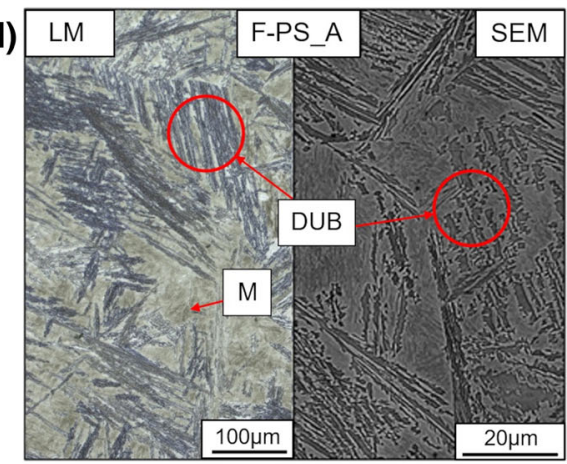

(f)

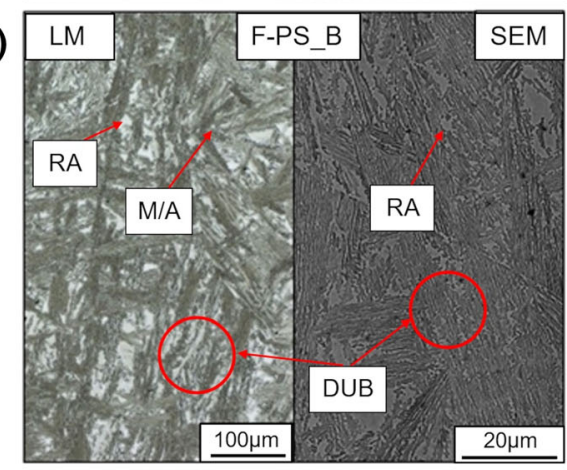

(h)

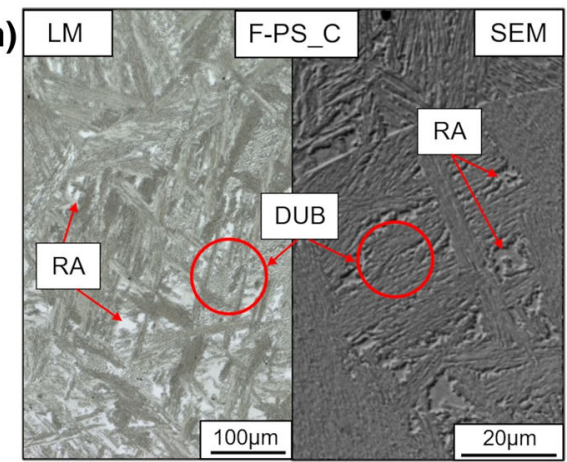

Fig. 5 Microstructures of the BS (a) and F-PS (b) in the initial state (DUB - degenerated upper bainite, M/A-martensite/austenite constituent, $\mathrm{M}-$ martensite, $\mathrm{P}$ - pearlite, $\mathrm{F}-$ ferrite) and BS (c, e, g) and F-PS (d, f, h) subjected to isothermal processing under different conditions 
Table 3. The volume fraction of different phases in BS and F-P steels [\%]

\begin{tabular}{llll}
\hline & Bainite & Martensite & Austenite \\
\hline BS & $82 \pm 6.5$ & $\ldots$ & $18 \pm 1.1$ \\
BS_A & $86 \pm 7.8$ & $10 \pm 0.9$ & $4 \pm 0.8$ \\
BS_B & $85 \pm 8.5$ & $7 \pm 0.6$ & $8 \pm 0.9$ \\
BS_C & $74 \pm 6.6$ & $\ldots$ & $26 \pm 1.4$ \\
F-PS_A & $75 \pm 5.9$ & $25 \pm 1.9$ & $\ldots$ \\
F-PS_B & $78 \pm 7.0$ & $12 \pm 1.2$ & $10 \pm 0.9$ \\
F-PS_C & $73 \pm 7.3$ & $\ldots$ & $27 \pm 1.3$ \\
\hline
\end{tabular}

RA islands in F-PS and BS was $11 \mu \mathrm{m}$ and $8 \mu \mathrm{m}$, respectively. Similar results were obtained for higher carbon bainitic steel (0.62C-1.47Si-0.85Mn-1.2Cr wt.\%), wherein decreasing the isothermal transformation temperature increased the amount of austenite and caused the bainite laths to become thinner (Ref 50, 51). Upon comparing the two steels, the differences in the size of the lamellar packets of bainite were clear. In the BS, the films of retained austenite located between the bainite laths were larger than those in the F-PS.

\subsection{Retained Austenite}

Differentiation of the isothermal transformation temperature caused differentiation of the volume fraction of retained austenite and the carbon content in this phase, as shown in Fig. 6. Under the applied heat treatment conditions, the volume fraction of RA increased as the bainitic treatment temperature decreased, regardless of the type of steel, and however, its stability depended on multiple factors, such as the carbon content in the austenite, its morphology and the volume fraction of this phase, as well as the type and morphology of the surrounding phases (Ref 52-54). When the temperature of the isothermal treatment was too high $\left(480{ }^{\circ} \mathrm{C}\right)$, the $(111)$ crystal lattice peak of the austenite in F-PS was not observed, indicating that the volume fraction of this phase was below the detection threshold of the XRD method. A reduction in the isothermal transformation temperature increased the carbon concentration in austenite, leading to austenite stabilization at $400{ }^{\circ} \mathrm{C}$. According to the theory, the content of the retained austenite should decrease as the temperature decreases, thus causing a subsequent increase in carbon content in the austenite. This relationship is true, provided that the bainitic transformation was stopped upon reaching the $T_{0}$ line. The RA fraction as a function of temperature may be influenced by a relatively short bainitic treatment time, which would limit the carbon diffusion and thus prevent its content in the austenite from reaching the $T_{0}$ line (Ref 55).

Microscopic observations revealed the presence of blocky retained austenite with martensite (M/A islands), as well as bainite. Careful observations indicated that on the left side of the reflexes from the bainitic ferrite (110) plane peak, there was a small peak with a lattice parameter that was close to the ferrite phase, which was identified as martensite. Austenite with a block morphology has lower stability and a lower carbon concentration, which contribute to its facile transformation into martensite. As the isothermal transformation temperature decreased, the appearance of a peak corresponding to the (111) crystal lattice plane of austenite was also observed. It is worth noting that for steel with an initial ferritic-pearlitic structure, an intense martensite peak was visible in the diffraction pattern after all variations of the isothermal treatment. In the BS_C subjected to thermal processing at $400{ }^{\circ} \mathrm{C}$, the amount of martensite was much smaller, and it was not detected in the XRD pattern (Fig. 6f). Following bainitic treatment at $400{ }^{\circ} \mathrm{C}$, the F-PS and BS samples exhibited their highest values of retained austenite $(27 \%$ and $26 \%$, respectively); this should be reflected in the mechanical properties of the specimens. The obtained results confirmed that the $T_{0}$ curve was not reached for all forms of austenite at higher temperatures of bainitic treatment. (More austenite was in the form of islands.) Well-balanced amounts of austenite-stabilizing elements (e.g., $\mathrm{Mn}, \mathrm{Cr}$, and $\mathrm{Ni}$ ) in the chemical compositions of the studied steels are expected to stabilize the austenite phase at room temperature (Ref 56, 57). The higher carbon content of the retained austenite in the F- PS samples was attributed to the combined addition of $\mathrm{Cr}$ and $\mathrm{Mn}$, which might have expelled carbon from the bainite into the coexisting austenite. It is known that carbon enrichment and the interactions between constituents play a crucial role in austenite stabilization, and similar conclusions were recently presented by Grajcar and Krztoń (Ref 58). The maximum fraction of retained austenite (mainly with an interlath morphology) occurred over a wide range of isothermal bainitic transformation temperatures, from 350 to $450{ }^{\circ} \mathrm{C}$.

\subsection{Mechanical Properties}

The mechanical properties of the investigated steel samples processed using different isothermal treatments are summarized in Fig. 7 and 8.

The investigated steels in the initial state exhibited similar total elongation but significantly different mechanical strengths, i.e., the BS was characterized by a higher yield strength $(750 \mathrm{MPa})$ and a higher ultimate tensile strength $(1250 \mathrm{MPa})$, but had a comparable total elongation to the F-PS $\left(\sigma_{0.2}=\right.$ $\left.470 \mathrm{MPa}, \sigma_{m}=810 \mathrm{MPa}\right)$. The applied heat treatment enhanced the strength of both investigated steel samples to a similar level $\left(\sigma_{m} \sim 1300-1400 \mathrm{MPa}\right)$ at the expense of their ductility. Both $\sigma_{m}$ and $\sigma_{0.2}$ showed a decreasing tendency as the isothermal transformation temperature decreased (Fig. 7). In contrast, the measured total elongation tended to increase as the bainitic treatment temperature decreased in relation to the heat treatment temperature. The observed differences were associated with the different volume fractions and morphological features of the structural constituents present in the investigated steels. Similar conclusions were obtained in the work of Pashangeh et al. (Ref 59), where the effect of retained austenite on mechanical properties was studied. The retained austenite with both blocky and thin-film morphologies in various heattreated samples considerably affects the stress-strain behaviour. In particular, the specimens with a high volume fraction of RA displayed high elongations due to the improved strain hardening capacity over a broad strain, mainly due to the TRIP effect. A very interesting parameter combining the balance between the strength and ductility is the $R_{x}$ (Figure 8). For samples with an initial ferritic-pearlitic structure, the value of the $R_{x}$ parameter was one and a half times higher than for the BS samples after all variations of the bainitic treatment. The exceptions are materials in the initial state, where the highest $R_{X}$ values were obtained for the bainitic steel. The F-PS_A samples after heat treatment did not show the presence of RA; hence, the value of the $R_{x}$ parameter was the lowest in this case. 

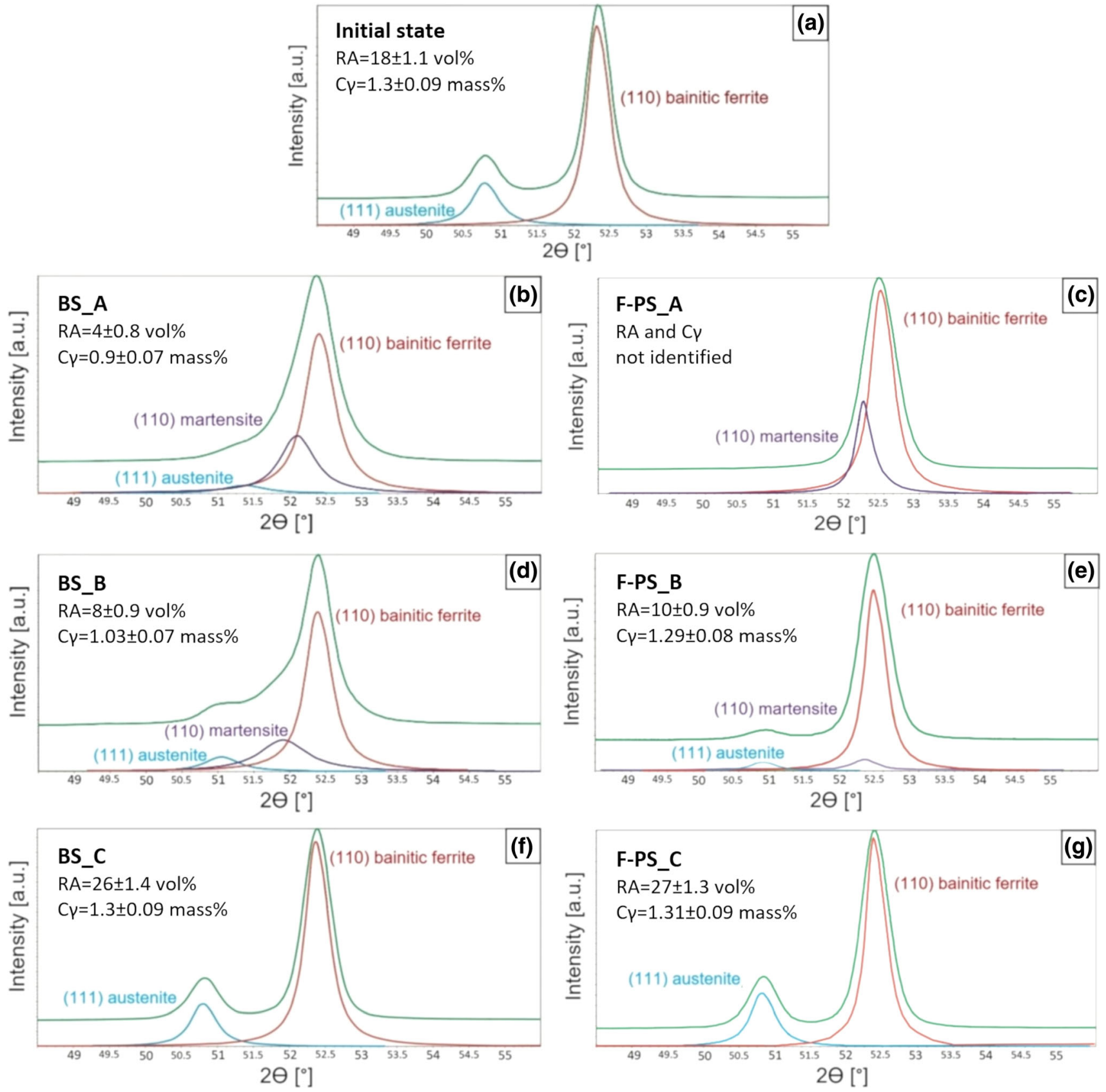

Fig. 6 XRD patterns of the BS (a, b, d, f) and F-PS (c, e, g) that were subjected to isothermal processing under different conditions

As the bainitic treatment temperature decreased, the degree of bainitic transformation increased, and the content of retained austenite also increased. The value of the $\mathrm{R}_{\mathrm{x}}$ parameter assumes a value similar to that of the initial state. Moreover, for BS samples, a lower temperature of the isothermal bainitic treatment and higher degree of bainitic transformation resulted in a change in the volume fraction of RA and increased the $R_{x}$ parameter. This is in agreement with the results of Junyu Tian et al. (Ref 60), who found that the best combinations of strength and ductility ( $25 \mathrm{GPaX} \%$ ) were obtained in steels by austempering below the $\mathrm{M}_{\mathrm{S}}$ (at $350^{\circ} \mathrm{C}$ ). This is related to optimizing the size and volume fraction of M/A constituents and the finer bainite microstructure. In contrast, the designed bainitic steel offered the best combination of strength and ductility directly after cooling. This means that the proposed chemical compo- sition and thermos-mechanical processing of the BS induced optimal properties after continuous cooling. Performing additional heat treatment processes is not necessary to improve the strength parameters and ductility of the material but will only increase the production costs of the finished product. This behavior of the material is related to the morphology of the retained austenite and its volume fraction. A lower strength and higher total elongation were observed as the amount of retained austenite increased as the isothermal bainitic treatment temperature decreased. Simultaneously, the volume fraction of the brittle martensitic phase decreased, which reduced the ultimate tensile strength and enhanced the plasticity. Therefore, this phenomenon was associated with the total fraction of the individual phases. It should also be noted that the samples containing a high fraction of martensite, such as F-PS_A (after 


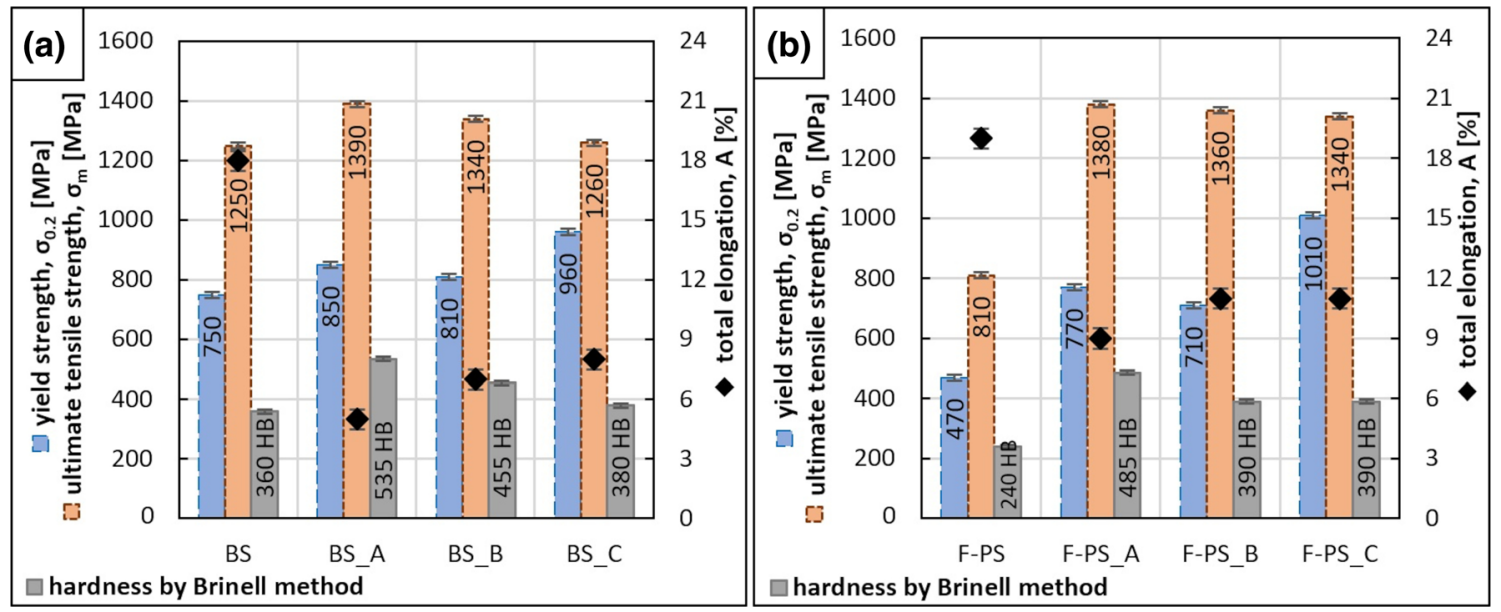

Fig. 7 Mechanical properties of BS (a) and F-PS (b) subjected to various heat treatment processing conditions; $\sigma_{0.2}$-yield strength, $\sigma_{\mathrm{m}}$ - ultimate tensile strength, A - total elongation, HB — hardness by Brinell method
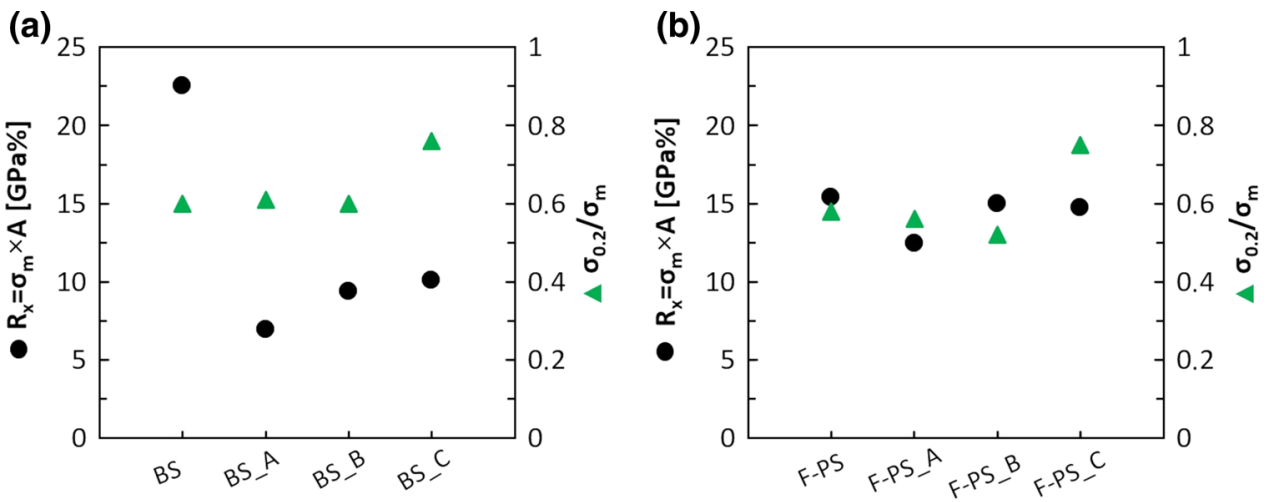

Fig. 8 Changes in the $\mathrm{R}_{\mathrm{x}}$ and $\sigma_{0.2} / \sigma_{\mathrm{m}}$ parameters for BS (a) and F-PS (b) steels subjected to various heat treatments and processing conditions

isothermal heat treatment at $480{ }^{\circ} \mathrm{C}$ ), and BS_A and BS_B (after isothermal transformation at $450{ }^{\circ} \mathrm{C}$ and $480{ }^{\circ} \mathrm{C}$, respectively), exhibited hardness values greater than $450 \mathrm{HB}$. The only exception from this tendency was the yield strength value of the samples after isothermal heat treatment at $400{ }^{\circ} \mathrm{C}$, and both F-PS_C and BS_C exhibited a significantly enhanced $\sigma_{0.2}$ $(\sim 1000 \mathrm{MPa})$. Since the volume fraction of the retained austenite in these samples was high (over 26\%), its transformation to martensite was highly likely during loading or deformation, owing to its lower carbon content and morphology. It should be noted that the increased $\sigma_{0.2}$ value and the lack of increase in $\sigma_{\mathrm{m}}$ may have been due to the presence of the retained austenite phase and decreasing martensite content. Its volume fraction in the structure $(25 \%)$ was responsible for the material's reaction to plastic deformation after exceeding a high value of yield strength. The retained austenite is a plastic phase, so the material did not exhibit higher tensile strength values. Although martensite is present in the structure, both materials begin to deform plastically at a lower stress level. This may be because of retained austenite in the form of thin films, which generate continuous agglomerates throughout the material, thus causing it to deform more easily. Furthermore, when the martensite appeared in the structure (up to $20 \%$ ) at the expense of other phases, $\sigma_{0.2}$ decreased and $\sigma_{m}$ increased (Ref 61).

Overall, it was concluded that in both investigated steels, the best combination of $\sigma_{0.2}, \sigma_{\mathrm{m}}$, and plasticity was attained after isothermal transformation at the lowest tested temperature. This was attributed to the thin films of RA between the laths of the fine bainite. The thin layer of the retained austenite with high carbon content was more stable than the blocky coarse RA, which could suppress microcracks initiation and hinder the propagation of cracks in the steel (Ref 10, 62, 63). Moreover, lowering the temperature of the austenite transformation into bainite increased the dislocation density in the bainite and its supersaturation with carbon, which contributes to a greater influence of the solution strengthening on the mechanical properties. In addition, the presence of substitute alloying elements, e.g., $\mathrm{Mn}, \mathrm{Cr}$, and Mo, improved the strength of the steels by lowering the temperature of isothermal bainite transformation and by solid solution strengthening of the steels (Ref 64, 65). In turn, the higher $\sigma_{0.2}$ and $\sigma_{\mathrm{m}}$ parameters for the bainitic steel were attributed to the finer bainite laths in the microstructure and the greater contribution of the grain refinement strengthening. By changing steel chemical composition and cooling conditions, it is possible to obtain various morphological types of bainite and modify the ratio of bainite to retained austenite. The achieved results are well correlated with the study of Qiangguo Li et al. (Ref 21). They investigated the effect of bainite on the mechanical properties of the microstructure in quenched and partitioned medium-carbon bainitic steel. The bainitic isothermal transformation process has been designed in which the different morphology and volume fractions of bainite are obtained during the transformation step. It should also be noted that in the present work, the 
application of isothermal bainitic treatment did not significantly improve the mechanical properties but only increases the processing time by introducing additional treatment with regard to continuous cooling.

There are numerous proposed relationships to describe the strain hardening behavior during tensile tests, including isotropic models, kinematic models, and combinations of these models (Ref 66-72). One common method for describing steel strain hardening involves the Hollomon equation (Ref 73-79), which was also used in this work. The obtained stress-strain curves allowed the determination of the strain hardening exponent $(\mathrm{n})$ and the strength coefficient $(\mathrm{K})$, as shown in Figure 9. Knowing the parameters $\mathrm{n}$ and $\mathrm{K}$ is essential during the formation of the final product. In the Hollomon equation, the $\mathrm{n}$ exponent measures the ability of a metal to strain-harden, and larger values indicate greater degrees of strain hardening. For most metals, the $\mathrm{n}$ parameter is in the range of $0.10-0.50$, however, perfectly elastic plastic-solids have a strain hardening exponent of zero ( $\operatorname{Ref} 80$ ). The $n$ exponent provides information about the material's ability to inhibit the localization of deformation. In other words, higher values of $\mathrm{n}$ indicate an increased rate at which the material is strengthened during deformation (Ref 81). Moreover, the $\mathrm{n}$ parameter is a measure of the material's formability during the tensile test, the greater the value of $\mathrm{n}$, the more uniformly the material is able to deform before the start of necking (Ref 82, 83). The value of the $K$ parameter provides an indication of the material's level of strength, and the forces required in forming. The $K$ value oscillates between $\mathrm{G} / 100$ and $\mathrm{G} / 1000$, where $G$ is the shear modulus. A good machinable material should have a low fracture toughness and a low strain hardening exponent. The increased strength (high value of the $K$ coefficient) ensures that local straining becomes more difficult, and that further strain occurs in the surrounding regions. This increases the local formability of the material in critical areas. Analysis of the tensile curves revealed that in both tested steels, the work
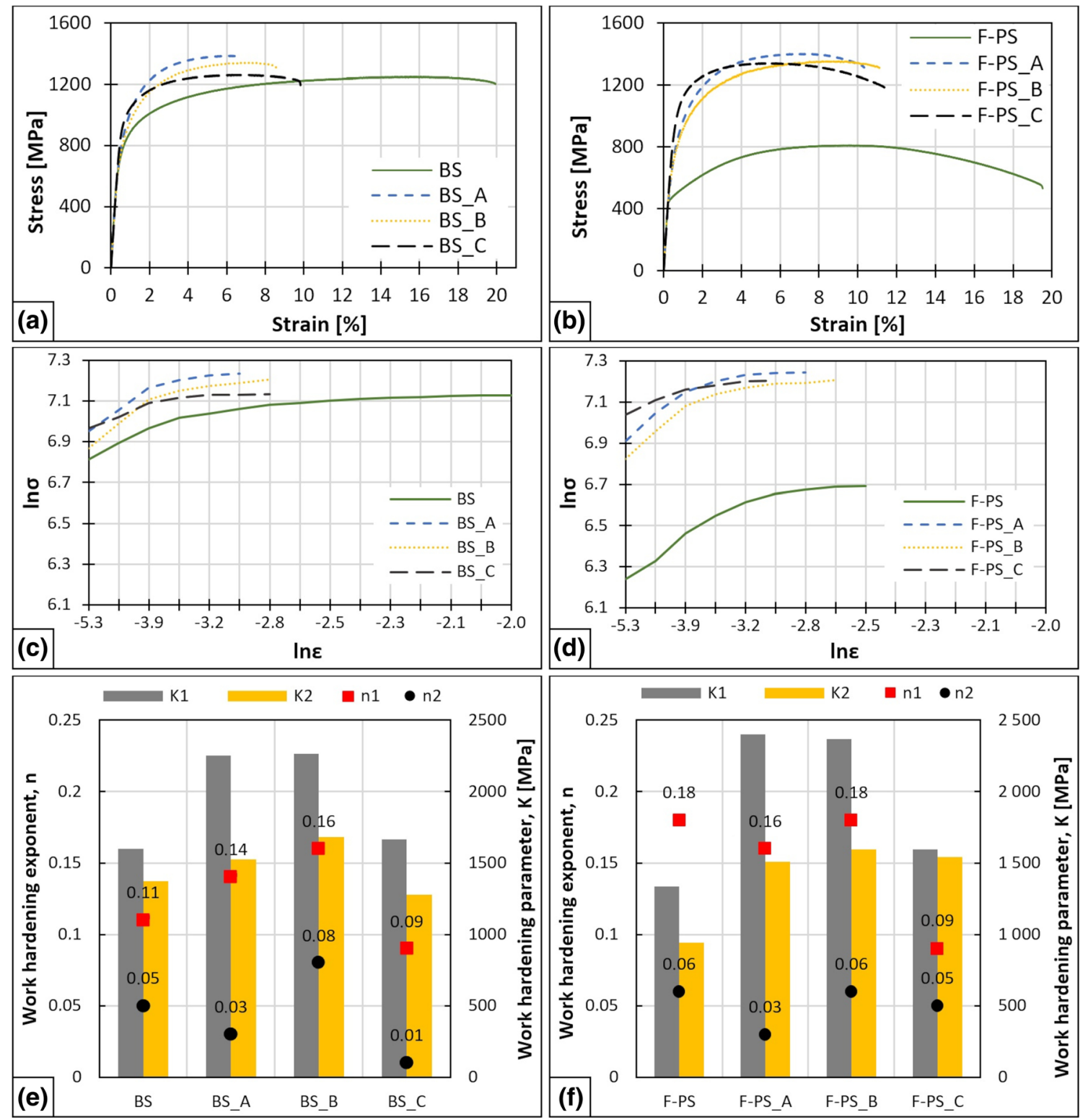

Fig. 9 Stress-strain curves for BS (a) and F-PS (b), ln-ln plot of true stress vs. true strain for BS (c) and F-PS (d), n and K parameters of BS (e) and F-PS (f) obtained following various heat treatment conditions 
hardening behavior could be divided into two stages with different slopes. The existence of distinct work hardening stages is related to different activated deformation mechanisms at the strain range corresponding to each state (Ref 74).

As shown in Fig. 9(a-b), all of the obtained stress-strain curves exhibited continuous yielding behavior (especially in the BS) and broader plateaus before necking. Considering the logarithmic distribution of the Hollomon equation, the nonlinear variation of $\ln \sigma$ with $\ln \varepsilon$ was obtained (Figure $9 \mathrm{c}-\mathrm{d}$ ). This means that the investigated steels were underwent a two-stage work hardening mechanism: The first stage had a high strainhardening exponent, while the second stage had a lower one. The different work hardening exponents result from several coexisting strengthening mechanisms. At $480{ }^{\circ} \mathrm{C}$, martensite was present in the microstructure of the steels, which increased the $\mathrm{K}$ and $\mathrm{n}$ parameters ( $\operatorname{Ref} 84$ ). Strengthening is attributed to the interaction of dislocation in martensite containing higher dislocation density (Ref 85 ). At $450{ }^{\circ} \mathrm{C}$, the microstructures of F-PS and BS consisted mainly of bainite and retained austenite in the form of islands (with various dimensions) and layers. The volume fraction of RA in the form of a layer increased significantly, and this type of austenite was stabilized by the compressive stress exerted by the surrounding bainite laths. The highly stable thin RA can contribute to inhibiting the initiation of cracks and affect increase of $\mathrm{n}$ and $\mathrm{K}$ parameters. Moreover, the chemical composition of the steel contained substitute alloying elements ( $\mathrm{Cr}, \mathrm{Mn}, \mathrm{Mo}$, and $\mathrm{Si}$ ), which strengthened the material by blocking dislocations in their initial positions and inhibiting their movement due to the limitation of cross-slip. Reducing the bainitic isothermal transformation temperature to $400{ }^{\circ} \mathrm{C}$ decreased the strain hardening exponent and the strength coefficient, while simultaneously increasing the volume fraction of the retained austenite. In this case, the bainitic transformation occurred to a greater extent than in the previously analyzed samples. In general, work hardening occurs due to changes in the movement, distribution, and density of mobile dislocations in the microstructure (Ref 86). Decreasing the $\mathrm{n}$ parameter and increasing the bainite volume fraction occur because of the smaller dislocation density present in the bainite. Krizan et al. (Ref 87) examined the tensile properties of micro-alloyed TRIP-aided steels and observed a decreasing strain hardening exponent with increasing isothermal hold time and temperature. This trend was expected because increasing the bainite volume fraction leads to a decrease in the strain hardening exponent. Furthermore, the microstructures of the steels were dominated by RA in the form of thin layers. In this case, the high proportion of soft retained austenite causes that the stresses generated during the static tensile test are absorbed by this phase (Ref 88,89$)$. In other words, the material did not strengthen as intensively as in the previous stage of the isothermal heat treatment process.

The strain hardening exponent and the strength coefficient of the second stage of work hardening were lower than those associated with the first stage. As the deformation during the tensile test increased, in the deformed microstructure, the dislocation tangles created during the initial hardening into cell structures were rearranged or annihilated, resulting in a rapid decrease of the $\mathrm{n}$ and $\mathrm{K}$ parameters.

Fig. 10 presents a comparison of the fracture surfaces (after tensile tests) of the bainitic and ferritic-pearlitic steels following various isothermal processing conditions. The fracture surfaces of all F-PS tensile samples were characterized by equiaxed dimples that suggested a ductile fracture mechanism.
After isothermal bainitic treatment, single faults were observed between the areas of plastic cracking. Quasi-cleavage was the dominant fracture mechanism for the BS samples. Numerous facets and cleavage planes characteristic of brittle fractures were also visible. Decreasing the isothermal transformation temperature increased the fraction of the plastic breakthrough, which was associated with an increase in the volume fraction of retained austenite. This effect increased the mixed character of the fractures, including quasi-cleavage fracture facets. The sample fractures indicated that as the transformation temperature decreased, the BS fracture became more plastic; more dimples were observed at the ridges of the fracture surface. The fine size of the dimples was attributed to the large volume fraction of bainite in the form of thin layers in the microstructure. A greater amount of bainite determines the number and distribution of micro-voids. This also contributed to the higher ductility of steel in this state (Ref 90, 91).

\section{Conclusions}

This work evaluated the compilation of bainitic steel in order to develop a new generation of rail steels. The microstructure of the bainitic steel in its continuous cooled state consisted of fine bainite, a thin film of RA, and the blocky austenite. The optimal combination of $\sigma_{m}(1250 \mathrm{MPa})$ and total elongation (18\%) was achieved by the BS after continuous cooling. The chemical composition of the steel was designed to obtain the optimal microstructure and mechanical properties after continuous cooling. The dimensions of the forged bars were chosen to achieve similar cooling conditions as in the rail head. The results of this study show that it is possible to design novel bainitic steel with lower production costs (fewer steps on the production line, low-carbon content, and alloying elements). The well-balanced amount of austenite-stabilizing elements (e. g., Mn, Cr, Ni) in the chemical compositions of the studied steel stabilized the austenite phase at room temperature and induced favorable mechanical properties. The main achievement of this study involved designing the chemical composition of the bainitic steel, such that the relationship between its strength and ductility was optimized after continuous cooling. In contrast, the application of isothermal transformation did not significantly improve the mechanical properties but only increased the technological process's time. Based on the obtained experimental results and a survey of the relevant literature, the following conclusions were drawn:

- Measurements of the retained austenite content in the steel samples via $\mathrm{x}$-ray diffraction indicated that the maximum volume fraction of this phase existed in samples that were subjected to isothermal bainitic transformation at $400{ }^{\circ} \mathrm{C}$. However, this phase was also present in large quantities in the BS sample after continuous cooling.

- The chemical composition of the bainitic steel after continuous cooling was balanced to obtain at least $90 \%$ of the degenerated upper bainite in the microstructure. This is much more difficult than conventional isothermal bainitic treatments.

- Decreasing the isothermal bainitic transformation temperature decreased its mechanical properties to a level close to that of its onset value. After bainitic treatment at $400{ }^{\circ} \mathrm{C}$, 

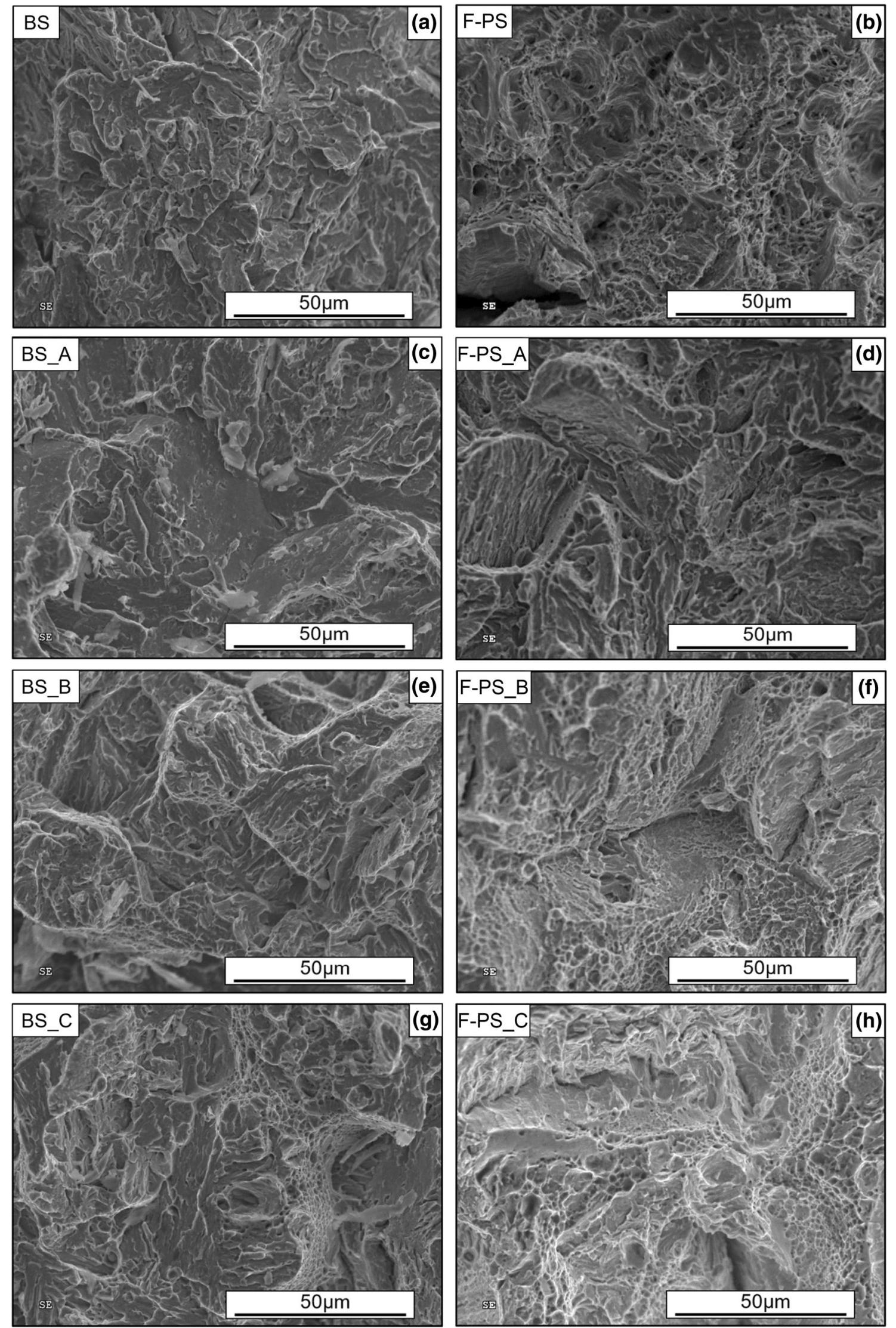

Fig. 10 SEM micrographs of the fracture surface of the BS (a, c, e, and g) and F-PS (b, d, f, and h) subjected to thermal processing under various different isothermal conditions 
there was a larger amount of retained austenite and a higher proof yield strength compared with those obtained after isothermal treating at higher temperatures.

- Comparing isothermal treatments for both the ferriticpearlitic and bainitic steel, an isothermal bainitic transformation at $400{ }^{\circ} \mathrm{C}$ led to a considerable increase in the materials' yield strengths, resulting from the more significant fraction and morphology of retained austenite in the samples. However, the best combination of ultimate tensile strength and total elongation was achieved by the BS after continuous cooling.

\section{Acknowledgments}

This work was supported by the National Centre for Research and Development - Project No.: PBS3/B5/39/2015 "Hybrid production technology of rails characterized by increased durability in the service conditions including future trends in the development of rail transport".

\section{Open Access}

This article is licensed under a Creative Commons Attribution 4.0 International License, which permits use, sharing, adaptation, distribution and reproduction in any medium or format, as long as you give appropriate credit to the original author(s) and the source, provide a link to the Creative Commons licence, and indicate if changes were made. The images or other third party material in this article are included in the article's Creative Commons licence, unless indicated otherwise in a credit line to the material. If material is not included in the article's Creative Commons licence and your intended use is not permitted by statutory regulation or exceeds the permitted use, you will need to obtain permission directly from the copyright holder. To view a copy of this licence, visit http://creativecommons.org/licenses/by/4.0/.

\section{References}

1. K.M. Lee and A.A. Polycarpou, Wear of Conventional Pearlitic and Improved Bainitic Rail Steels, Wear, 2005 https://doi.org/10.1016/j. wear.2005.02.058

2. H. Soleimani and M. Moavenian, Aspects of Wheel-Rail Contact: A Review of Wear Mechanisms and Effective Factors on Rolling Contact Fatigue, Urban Rail Transit., 2017 https://doi.org/10.1007/s40864-01 7-0072-2

3. Y. Hu, L. Zhou, H.H. Ding, G.X. Tan, R. Lewis, Q.Y. Liu, J. Guo and W.J. Wang, Investigation on Wear and Rolling Contact Fatigue of Wheel-Rail Materials Under Various Wheel/Rail Hardness Ratio and Creepage Conditions, Tribol. Int., 2020 https://doi.org/10.1016/j.trib oint.2019.106091

4. B. Panda, R. Balasubramaniam and A. Moon, Microstructure and Mechanical Properties of Novel Rail Steels, Mater. Sci. Technol., 2009 https://doi.org/10.1179/174328408X385764

5. A. Kumar, S.K. Makineni, A. Dutta, C. Goulas, M. Steenbergen, R.H Petrov and J. Sietsma, Design of High-Strength and Damage-Resistant Carbide-free Fine Bainitic Steels for Railway Crossing Applications, Mater. Sci. Eng. A, 2019 https://doi.org/10.1016/j.msea.2019.05.043

6. A. Kapito, W. Stumpf and M.J. Papo, The Role of Alloying Elements in Bainitic Rail Steels, J. S. Afr. Inst. Min. Metall., 2013, 113(2), p 67 72

7. M. Masoumi, E.A. Echeverri, A.P. Tschiptschin and H. Goldenstein, Improvement of Wear Resistance in a Pearlitic Rail Steel Via
Quenching and Partitioning Processing, Sci Rep., 2019 https://doi.or g/10.1038/s41598-019-43623-7

8. I.I. Gorbachev, V.V. Popov and A.Y. Pasynkov, Calculations of the Influence of Alloying Elements (Al, Cr, Mn, Ni, Si) on the Solubility of Carbonitrides in Low-Carbon Low-Alloy Steels, Phys. Metals Metallogr., 2016 https://doi.org/10.1134/S0031918X16120061

9. L. Qian, Q. Zhou, F. Zhang, J. Meng, M. Zhang and Y. Tian, Microstructure and Mechanical Properties of a Low Carbon CarbideFree Bainitic Steel co-Alloyed with Al and Si, Mater. Des., 2012 h ttps://doi.org/10.1016/j.matdes.2012.02.053

10. O. Hajizad, A. Kumar, Z. Li, R.H. Petrov, J. Sietsma and R. Dollevoet, Influence of Microstructure on Mechanical Properties of Bainitic Steels in Railway Applications, Metals, 2019 https://doi.org/10.3390/met90 70778

11. H.K.D.H. Bhadeshia, High Performance Bainitic Steels, Mater. Sci. Forum., 2005 https://doi.org/10.4028/www.scientific.net/MSF.500-50 1.63

12. K. Sawley and J. Kristan, Development of Bainitic Rail Steels with Potential Resistance to Rolling Contact Fatigue, Fatigue Fract. Eng. Mater. Struct., 2003 https://doi.org/10.1046/j.1460-2695.2003.00671.x

13. J. Zhang, H. Di, Y. Deng and R.D.K. Misra, Effect of Martensite Morphology and Volume fraction on Strain Hardening and Fracture Behavior of Martensite-Ferrite Dual Phase Steel, Mater. Sci. Eng. A., 2015 https://doi.org/10.1016/j.msea.2015.01.006

14. L. Qu, W. Dabboussi, F. Hassani, J.A. Nemes and S. Yue, Effect of Microstructure and Chemical Composition on Dynamic Factor of High Strength Steels, Mater. Sci. Tech., 2008 https://doi.org/10.1179/17432 8408X307247

15. K. Radwanski, Structural Characterization of Low-Carbon Multiphase Steels Merging Advanced Research Methods with Light Optical Microscopy, Arch. Civil. Mech. Eng., 2016 https://doi.org/10.1016/j.ac me.2015.12.001

16. M.M. Blaoui, M. Zemri and A. Brahami, Effect of Heat Treatment Parameters on Mechanical Properties of Medium Carbon Steel, Mech. Mech. Eng., 2018 https://doi.org/10.2478/mme-2018-0071

17. O. Ríos-Diez, R. Aristizábal-Sierra, C. Serna-Giraldo, J.A. Jimenez and C. Garcia-Mateo, Development of Nanobainitic Microstructures in Carbo-Austempered Cast Steels: Heat Treatment, Microstructure and Properties, Metals, 2020 https://doi.org/10.3390/met10050635

18. M.N. Yoozbashi, S. Yazdani and T.S. Wang, Design of a New Nanostructured, High-si Bainitic Steel with Lower Cost Production, Mater. Des., 2011 https://doi.org/10.1016/j.matdes.2011.02.031

19. X.Y. Long, J. Kang, B. Lv and F.C. Zhang, Carbide-Free Bainite in Medium Carbon Steel, Mater. Des., 2014 https://doi.org/10.1016/j.ma tdes.2014.07.055

20. S. Chen, R. Mostert and M. Aarnts, Microstructure and Properties of an Advanced High-Strength Steel After Austempering Treatment, Mater. Sci. Tech., 2021 https://doi.org/10.1080/02670836.2021.1940425

21. Q. Li, Y. Zhang, W. Li, X. Huang and W. Huang, Improved Mechanical Properties of a Quenched and Partitioned Medium-Carbon Bainitic Steel by Control of Bainitic Isothermal Transformation, J. Mater. Eng. Perform., 2020 https://doi.org/10.1007/s11665-020-04554-x

22. Y. Han, W. Xiu, C. Liu and H. Wu, Isothermal Transformation of a Commercial Super-Bainitic Steel: Part I Microstructural Characterization and Hardness, J. Mater. Eng. Perform., 2017 https://doi.org/10. 1007/s11665-016-2473-x

23. https://www.transvalor.com/en/forge

24. A. Milenin, W. Zalecki, M. Pernach, L. Rauch, R. Kuziak, T. Zygmunt and M. Pietrzyk, Numerical Simulation of Manufacturing Process Chain for Pearlitic and Bainitic Steel Rails, Archiv. Civ. Mech. Eng, 2020 https://doi.org/10.1007/s43452-020-00107-0

25. C.F. Jatczak, Retained Austenite and its Measurement by x-ray Diffraction, SAE Trans., 1980 https://doi.org/10.4271/800426

26. C.Y. Wang, J. Shi, W.Q. Cao and H. Dong, Characterization of Microstructure Obtained by Quenching and Partitioning Process in Low Alloy Martensitic Steel, Mater. Sci. Eng. A, 2010 https://doi.org/ 10.1016/j.msea.2010.02.020

27. B.D. Cullity, Elements of X-ray diffraction, 2nd ed. Addision-Wesley Publishing Company, Boston, 1978

28. J.H. Hollomon, Tensile Deformation, Trans. Metall. Soc. AIME, 1945, 162, p 268-290

29. S. Zajac, V. Schwinn and K.H. Tacke, Characterisation and Quantification of Complex Bainitic Microstructures in High and Ultra-High 
Strength Linepipe Steels, Mater. Sci. Forum., 2005 https://doi.org/10. 4028/www.scientific.net/MSF.500-501.387

30. Y.M. Kim, S.Y. Shin, H. Lee, B. Hwang, S. Lee and N.J. Kim, Effects of Molybdenum and Vanadium Addition on Tensile and Charpy Impact Properties of API X70 Linepipe Steels, Metall. Mater. Trans. A, $2007 \mathrm{~h}$ ttps://doi.org/10.1007/s11661-007-9197-3

31. G.N. Haidemenopoulos and A.N. Vasilakos, Modelling of Austenite Stability in Low- Alloy Triple-Phase Steels, Steel Res., 1996, 67(11), p 513-519

32. X.Y. Long, F.C. Zhang and C.Y. Zhang, Effect of Mn Content on LowCycle Fatigue Behaviors of Low-Carbon Bainitic Steel, Mater. Sci. Eng. A, 2017 https://doi.org/10.1016/j.msea.2017.04.089

33. M.L. Brandt and G.B. Olson, Bainitic stabilization of austenite in low alloy sheet steels, Iron Steel Magazine, (1993), p. 257-265

34. M. Zhang, J. Qian and H. Gu, The Structure Stability of Carbide-Free Bainite Wheel Steel, J. Mater. Eng. Perform., 2007 https://doi.org/10. 1007/s11665-007-9079-2

35. P. Jacques, E. Girault, T. Catlin, N. Geerlofs, T. Kop, S. Zwaag and F. Delannay, Bainite Transformation of Low carbon Mn-Si TRIPAssisted Multiphase Steels: Influence of Silicon Content on Cementite Precipitation and Austenite Retention, Mater. Sci. Eng. A, 1999 http s://doi.org/10.1016/S0921-5093(99)00331-7

36. E. Kozeschnik and H.K.D.H. Bhadeshia, Influence of Silicon on Cementite Precipitation in Steels, Mater. Sci. Tech., 2008 https://doi. org/10.1179/174328408X275973

37. Z. Guo-Hong, C. Jae-Yong, K. Kwan-Ho and S. Dong Woo, Effects of $\mathrm{Mn}, \mathrm{Si}$ and $\mathrm{Cr}$ Addition on the Dissolution and Coarsening of Pearlitic Cementite During Intercritical Austenitization in Fe-1mass\%C Alloy, Mater. Charact., 2013 https://doi.org/10.1016/j.matchar.2013.04.007

38. R. Ordóñez Olivares, C.I. Garcia, A. DeArdo, S. Kalay and F.C. Robles Hernández, Advanced metallurgical alloy design and thermomechanical processing for rails steels for North American heavy haul use, Wear, 2011 https://doi.org/10.1016/j.wear.2010.10.048

39. S.M. Hasan, M. Ghosh, D. Chakrabarti and S.B. Singh, Development of Continuously Cooled Low-Carbon, Low-Alloy, High Strength Carbide-Free Bainitic Rail Steels, Mater. Sci. Eng. A, 2020 https://d oi.org/10.1016/j.msea.2019.138590

40. H. Kong, Q. Chao, M.H. Cai, E.J. Pavlina, B. Rolfe, P.D. Hodgson and H. Beladi, Microstructure Evolution and Mechanical Behavior of a CMnSiAl TRIP Steel Subjected to Partial Austenitization Along with Quenching and Partitioning Treatment, Metall. Mater. Trans. A, $2018 \mathrm{~h}$ ttps://doi.org/10.1007/s11661-018-4525-3

41. J.W. Jin, C. Park and N. Kang, Isothermal Phase Transformations and Stability of Retained Austenite During Quenching and Partitioning Process for 015C Steel, J. Weld. Join., 2017 https://doi.org/10.5781/ JWJ.2017.35.1.89

42. J.C.F. Jorge, L.F.G. Souza and J.M.A. Rebello, The Effect of Chromium on the Microstructure/Toughness Relationship of C-Mn Weld Metal Deposits, Mater. Charact., 2001 https://doi.org/10.1016/ S1044-5803(01)00168-1

43. J. Tian, G. Xu, M. Zhou, H. Hu and X. Wan, The Effects of $\mathrm{Cr}$ and Al Addition on Transformation and Properties in Low-Carbon Bainitic Steels, Metals, 2017 https://doi.org/10.3390/met7020040

44. L.Y. Zhou, Y.Z. Liu, F. Yuan, Q.W. Huang and R.B. Song, Effect of Cr on Transformation of Ferrite and Bainitedual Phase Steels, J. Iron Steel Res. Int., 2009, 21, p 37-41

45. J. Kang, F.C. Zhang, X.W. Yang, B. Lv and K.M. Wu, Effect of Tempering on the Microstructure and Mechanical Properties of a Medium Carbon Bainitic Steel, Mater. Sci. Eng. A, 2017 https://doi.org/ 10.1016/j.msea.2017.01.044

46. H. Hu, G. Xu, M. Zhou and Q. Yuan, Effect of Mo Content on Microstructure and Property of Low-Carbon Bainitic Steels, Metals, 2016 https://doi.org/10.3390/met6080173

47. M.N. Yoozbashi and S. Yazdani, Mechanical Properties of Nanostructured, Low Temperature Bainitic Steel Designed Using a Thermodynamic Model, Mater. Sci. Eng. A, 2010 https://doi.org/10.1016/j.msea. 2010.01.080

48. A. Navarro-López, J. Hidalgo, J. Sietsma and M.J. Santofimia, Characterization of Bainitic/Martensitic Structures Formed in Isothermal Treatments Below the Ms Temperature, Mater. Charact., $2017 \mathrm{~h}$ ttps://doi.org/10.1016/j.matchar.2017.04.007

49. J. Meng, Y. Feng, Q. Zhou, L. Zhao, F. Zhang and L. Qian, Effects of Austempering Temperature on Strength, Ductility and Toughness of
Low-C High-Al/Si Carbide-Free Bainitic Steel, J. Mater. Eng. Perform., 2018 https://doi.org/10.1007/s11665-015-1567-1

50. N. Liu, X. Zhang, J. Ding, J. He and F.X. Yin, Microstructure and Mechanical Properties of Nanobainitic Steel Subjected to Multiple Isothermal Heat Treatments, J. Iron Steel Res. Int., 2018 https://doi.org/ 10.1007/s42243-018-0156-6

51. B. Adamczyk-Cieślak, M. Koralnik, R. Kuziak, M. Smaczny, T. Zygmunt and J. Mizera, Effects of Heat Treatment Parameters on the Microstructure and Properties of Bainitic Steel, J. Mater. Eng. Perform., 2019 https://doi.org/10.1007/s11665-019-04452-x

52. R. Hossain, F. Pahlevani and V. Sahajwalla, Stability of Retained Austenite in High Carbon Steel - Effect of Post-Tempering Heat Treatment, Mater. Charact., 2019 https://doi.org/10.1016/j.matchar.20 19.01.034

53. J. Hidalgo, K.O. Findley and M.J. Santofimia, Thermal and Mechanical Stability of Retained Austenite Surrounded by Martensite with Different Degrees of Tempering, Mater. Sci. Eng. A, 2017 https://doi. org/10.1016/j.msea.2017.03.017

54. S.H. He, B.B. He, K.Y. Zhu, R. Ding, H. Chen and M.X. Huang, Revealing the Role of Dislocations on the Stability of Retained Austenite in a Tempered Bainite, Scr. Mater., 2019 https://doi.org/10. 1016/j.scriptamat.2019.04.019

55. S. Mohammad, K. Hosseini, A. Zarei-Hanzaki and S. Yue, Microstructure Development and Mechanical Properties of Low-Silicon-Content TRIP-Assisted Steels After Coiling Process, Steel Res. Int., $2016 \mathrm{~h}$ ttps://doi.org/10.1002/srin.201400525

56. M. Soliman and H. Palkowski, Development of the Low Temperature Bainite, Arch. Civil Mech. Eng., 2016 https://doi.org/10.1016/j.acme. 2016.02.007

57. Z. Changle, F. Hanguang, M. Shengqiang, Y. Dawei, L. Jian, X. Zhenguo and L. Yongpin, Effect of Mn Content on Microstructure and Properties of Wear-Resistant Bainitic Steel, Mater. Res. Express, 2019 https://doi.org/10.1088/2053-1591/ab1c8d

58. A. Grajcar and H. Krztoń, Effect of Isothermal Holding Temperature on Retained Austenite Fraction in Mediumcarbon Nb/Ti-Microalloyed TRIP Steel, J. Achiev. Mater. Manuf. Eng., 2011, 49, p 391-399

59. S. Pashangeh, M. Somani, S. Sadegh and G. Banadkouki, StructureProperty Correlations of a Medium C Steel Following Quenching and Isothermal Holding Above and Below the MS Temperature, ISIJ Int., $2021 \mathrm{https}$ //doi.org/10.2355/isijinternational.ISIJINT-2020-355

60. J. Tian, G. Xu, H. Hu, X. Wang and H. Zurob, Transformation Kinetics of Carbide-Free Bainitic Steels During Isothermal Holding Above and Below MS, J. Mater. Res. Technol., 2020 https://doi.org/10.1016/j.jmrt. 2020.09.119

61. N. Fonstein, M. Kapustin, N. Pottore, I. Gupta and I. Yakubovsky, Factors that Determine the Level of the Yield Strength and the Return of the YieldPoint Elongation in Low-Alloy Ferrite-Martensite Steels, Phys. Metals Metallogr., 2007 https://doi.org/10.1134/S0031918X07090153

62. A. Królicka, G. Lesiuk, K. Radwański, R. Kuziak, A. Janik, R. Mech and T. Zygmunt, Comparison of Fatigue Crack Growth Rate: Pearlitic Rail Versus Bainitic Rail, Int. J. Fatigue, 2021 https:/doi.org/10.1016/ j.ijfatigue.2021.106280

63. J.A. Cruz, T.F.M. Rodrigues, V.D.C. Viana, H. Abreu and D.B. Santos, Influence of Temperature and Time of Austempering Treatment on Mechanical Properties of SAE 9254 Commercial Steel, Steel Res. Int., 2012, 83(1), p 22-31

64. V. Bordereau, Quantitative Relationships Between Chemical Composition, Microstructure and Mechanical Properties for Bainitic Steels, Materials. Ecole Nationale Supérieure des Mines de Paris, (2015), English. HAL Id: tel-02892101, https://pastel.archives-ouvertes.fr/tel$02892101 \mathrm{v} 2$

65. M. Arribas, T. Gutiérrez, E. Del Molino, A. Arlazarov, I. De DiegoCalderón, D. Martin, D. Caro, S. Ayenampudi and M.J. Santofimia, Austenite Reverse Transformation in a Q\&P Route of $\mathrm{Mn}$ and $\mathrm{Ni}$ Added Steels, Metals, 2020 https://doi.org/10.3390/met10070862

66. H. Ashrafi, M. Shamanian, R. Emadi and N. Saeidi, Microstructure, Tensile Properties and Work Hardening Behavior of GTA-Welded Dual-Phase Steels, J. Mater. Eng. Perform., 2017 https://doi.org/10. 1007/s11665-017-2544-7

67. S. Bouvier, J.L. Alves, M.C. Oliveira and L.F. Menezes, Modelling of Anisotropic Work-Hardening Behavior of Metallic Materials Subjected to Strain-Path Changes, Comput. Mater Sco., 2005 https://doi.org/10. 1016/j.commatsci.2004.09.038 
68. B. Berisha, P. Hora, A. Wahlen and L. Tong, A Combined IsotropicKinematic Hardening Model for the Simulation of Warm Forming and Subsequent Loading at Room Temperature, Inter. J. Plast., 2010 h ttps://doi.org/10.1016/j.ijplas.2009.06.001

69. M. Wójcik and A. Skrzat, Identification of Chaboche-Lemaitre Combined Isotropic-Kinematic Hardening Model Parameters Assisted by the Fuzzy Logic Analysis, Acta Mech., 2020 https://doi.org/10.10 07/s00707-020-02851-z

70. R. Li, P. Eyckens, E. Daxin, J. Gawad, M. Van Poucke, S. Coorema and A. Van Bael, Advanced Plasticity Modeling for Ultra-Low-CycleFatigue Simulation of Steel Pipe, Metals, 2017 https://doi.org/10.3390/ met7040140

71. V. Kilicli and M. Erdogan, The Strain-Hardening Behavior of Partially Austenitized and the Austempered Ductile Irons with Dual Matrix Structures, J. Mater. Eng. Perform., 2008 https://doi.org/10.1007/s11 665-007-9143-y

72. H. Mecking and U.F. Kocks, Kinetics of Flow and Strain-Hardening, Acta Metall. Mater, 1981 https://doi.org/10.1016/0001-6160(81)90112-7

73. Q. Li, X. Huang and W. Huang, Microstructure and Mechanical Properties of a Medium-Carbon Bainitic Steel by a Novel Quenching and Dynamic Partitioning (Q-DP) Process, Mater. Sci. Eng. A., 2016 h ttps://doi.org/10.1016/j.msea.2016.03.042

74. M.M. Karimi, S. Kheirandish and U.U. Gomes, Study on work hardening behavior of ferritic-bainitic dual phase steels, $22^{\circ} \mathrm{CBECiMat}$ - Congresso Brasileiro de Engenharia e Ciência dos Materiais (2016), Natal, RN, Brasil p 6226-6235

75. J.C. Hell, M. Dehmas, S. Allain, J. Mendes Prado, A. Hazotte and J.P Chateau, Microstructure-Properties Relationships in Carbide-Free Bainitic Steels, ISIJ Int., 2011 https://doi.org/10.2355/isijinternational.51.1724

76. J. Zhang, H. Di, Y. Deng and R.D.K. Misra, Effect of Martensite Morphology and Volume Fraction on Strain Hardening and Fracture Behavior of Martensite-Ferrite Dual Phase Steel, Mater. Sci. Eng. A, 2015 https://doi.org/10.1016/j.msea.2015.01.006

77. P. Luo, G. Gao, H. Zhang, Z. Tan, R.D.K. Misra and B. Bai, On Structure-Property Relationship in Nanostructured Bainitic steel Subjected to the Quenching and Partitioning Process, Mater. Sci. Eng. A, 2016 https://doi.org/10.1016/j.msea.2016.03.006

78. E. Liu, Q. Li, S. Naseem, X. Huang and W. Huang, Effect of Isothermal Transformation Times Below Ms and Tempering on Strength and Toughness of Low-Temperature Bainite in $0.53 \mathrm{C}$ Bainitic Steel, Materials, 2020 https://doi.org/10.3390/ma13102418

79. O. Hajizad, A. Kumar, Z. Li, R.H. Petrov, J. Sietsma and R. Dollevoet, Influence of Microstructure on Mechanical Propertiesof Bainitic Steels in Railway Applications, Metals, 2019 https://doi.org/10.3390/met90 70778

80. R.K. Nutor, N.K. Adomako and Y.Z. Fang, Using the Hollomon Model to Predict Strain-Hardening in Metals, Am. J. Mater. Syn. Proc., $2017 \mathrm{~h}$ ttps://doi.org/10.11648/j.ajmsp.20170201.11

81. M.R. Akbarpour and A. Ekrami, Effect of Ferrite Volume Fraction on Work Hardening Behavior of High Bainite Dual Phase (DP) Steels, Mater. Sci. Eng. A, 2008, 477(1-2), p 306-310

82. R.W. Hertzberg, Deformation and fracture mechanics of engineering materials, Wiley, USA, 1996

83. J. Datsko, Material properties and manufacturing processes, Wiley, New York, 1966

84. A. Zare and A. Ekrami, Effect of Martensite Volume Fraction on Work Hardening Behavior of Triple Phase (TP) Steels, Mater. Sci. Eng. A, 2011 https://doi.org/10.1016/j.msea.2011.02.021

85. H. Rastegari, A. Kermanpur and A. Najafizadeh, Effect of Initial Microstructure on the Work Hardening Behavior of Plain Eutectoid Steel, Mater. Sci. Eng. A, 2015 https://doi.org/10.1016/j.msea.2015.02. 040

86. D. Hull and D.J. Bacon, Introduction to Dislocations, Elsevier 1td., Oxford, UK, 2011

87. D. Krizan and B.C. De Cooman, Analysis of the Strain-Induced Martensitic Transformation of Retained Austenite in Cold Rolled Micro-Alloyed TRIP Steel, Steel Res. Inter., 2008, 79, p 513-522

88. H. Lan, L. Du, N. Zhou and X. Liu, Effect of Austempering Route on Microstructural Characterization of Nanobainitic Steel, Acta. Metall. Sin. Engl. Lett., 2004 https://doi.org/10.1007/s40195-013-0006-2

89. S.M. Hasan, A. Mandal, S.B. Singh and D. Chakrabarti, Work Hardening Behaviour and Damage Mechanisms in Carbide-Free Bainitic Steel during Uni-Axial Tensile Deformation, Mater. Sci. Eng. A, 2019 https://doi.org/10.1016/j.msea.2019.02.062

90. A. Kumar, S.B. Singh and K.K. Ray, Influence of Bainite/MartensiteContent on the Tensile Properties of Low Carbon Dual-Phase Steels, Mater. Sci. Eng. A, 2008 https://doi.org/10.1016/j.msea.2007.05.007

91. S. Das, S. Sinha, A. Lodh, A.R. Chintha, M. Krugla and A. Haldar, Hot-Rolled and Continuously Cooled Bainitic Steel with Good Strength-Elongation Combination, Mater. Sci. Tech., 2017 https://doi. org/10.1080/02670836.2016.1268663

Publisher's Note Springer Nature remains neutral with regard to jurisdictional claims in published maps and institutional affiliations. 